Archived version from NCDOCKS Institutional Repository http://libres.uncg.edu/ir/asu/

\title{
Appalachl̈an
}

B O O N E, NORT H CAROL I N A

Daly, Brian P.; Jameson, John Paul;

Patterson, Freda; McCurdy, Mark; Kirk, Alex; Michael, Kurt D., (2015) Sleep

Duration, Mental Health, and Substance

Use Among Rural Adolescents:

Developmental Correlates. Published in

Journal of Rural Mental Health, 39(2),

108-122 DOI: 10.1037/rmh0000033 ISSN:

1935-942X Published April 2015 


\title{
Sleep Duration, Mental Health, and Substance Use Among Rural Adolescents: Developmental Correlates
}

\author{
Brian P. Daly, Freda Patterson, John Paul \\ Jameson, Mark McCurdy, Alex Kirk, and \\ Kurt D. Michael
}

\begin{abstract}
Numerous studies have demonstrated that most adolescents do not get adequate amounts of sleep. Furthermore, insufficient sleep is associated with increased risk for depression and suicide attempts as well as substance abuse in adolescence. However, extant studies have relied primarily on national samples or suburban adolescents, with a paucity of research examining the associations between sleep duration and mental health and substance abuse risk in rural adolescents. Additionally, these associations rarely have been examined within a developmental context. The present study attempted to address these gaps by using data from the Youth Risk Behavior Survey (YRBS) to examine the associations between sleep duration and risk factors in the lower and upper grade levels for high school students attending schools in rural areas. YRBS data were obtained from 2 rural school districts located in the Appalachian region of North Carolina $(n=987)$. For the full sample, approximately $40 \%$ of students reported receiving 6 or fewer hours of sleep on a typical school night. High school students in the lower grades (9th and 10th) who reported short sleep duration were more likely to have endorsed each of the mental health, suicidal behavior, and substance use items. Significant differences emerged between sleep groups on suicide attempts and alcohol, tobacco, and marijuana use for students in the upper grade levels. We conclude that short sleep duration is problematic in rural high school students, especially for those students recently transitioning from middle school to high school. These findings can inform identification, prevention, and intervention strategies to encourage and promote healthy sleep habits among rural adolescents.
\end{abstract}

Insufficient sleep, particularly during adolescence, is considered a significant public health problem because of high prevalence rates as well as detrimental impacts on important physical, emotional, and cognitive functioning. Al-though it has been suggested that adolescents physiologically require 9 to 10 hours of sleep per night (Carskadon, Acebo, \& Jenni, 2004; National Sleep Foundation, 2006; Strauch, 2003), results from a recent national survey reveal that less than $10 \%$ of high school stu-dents reported receiving the recommended 9 or more hours of sleep on an average school night (Eaton et al., 2010). Findings from a similar survey indicated a high prevalence of very short sleep duration with nearly $44 \%$ of high school female students and $36 \%$ of male students getting 6 or fewer hours of sleep per school night (Basch, Basch, Ruggles, \& Rajan, 2014). 
Equally concerning is that the overall prevalence of insufficient sleep problems in youth has increased significantly over time, with $31.2 \%$ reporting fewer than seven days per week of adequate sleep in 2003 as compared with $41.9 \%$ in 2011 through 2012 (Singh \& Kenney, 2013).

From a biological perspective, changes that begin as early as puberty impact the circadian rhythms of adolescents and result in "sleep phase delay" in which sleep onset occurs later at night and waking occurs later in the morning (Dahl \& Lewin, 2002). Adolescents as a group receive less sleep than adults and children (Mantz, Muzet, \& Winter, 2000). School start times, academic demands, extracurricular activities, and nighttime distractions such as watching TV or engaging in social or electronic media use are some of the environmental and behavioral factors that influence teenage sleep patterns. Essentially, a conflict emerges during the adolescent period between the physiological need for sufficient sleep and environmental factors that serve to reduce the length of total sleep time, ultimately resulting in adverse psychosocial, behavioral, and physical consequences for healthy adolescent development.

\section{Adolescent Mental Health and Sleep}

Teenagers experience myriad psychosocial challenges, among the most concerning of which is the risk for depression and suicidal behavior. Findings from the extant literature reveal that short sleep duration significantly impacts teenagers' mental health such that they are more likely to experience higher levels of depressive symptoms (Dahl \& Lewin, 2002; McKnight-Eily et al., 2011; O’Brien \& Mindell, 2005; Roberts, Roberts, \& Chen, 2001). For example, youth who experience insufficient sleep during the week have 4 to 5 times higher risks of depression relative to youth who have no sleep problems during the week (National Center for Health Statistics, 2009). In a prospective analysis, Roberts and Duong (2014) examined sleep deprivation, or short sleep, and symptoms of depression in a cohort of more than 3,000 adolescents. Over a one-year span, researchers found that sleep deprivation at baseline predicted depressive symptoms at follow-up after controlling for baseline depression levels. Moreover, major depression at baseline predicted sleep deprivation at follow-up, sug- gesting a reciprocal association between these factors.

Studies that have examined sleep and suicidal behavior have found increased risk for suicidal thoughts or behaviors among those adolescents reporting insufficient sleep (Do, Shin, Bautista, \& Foo, 2013; Johnson \& Breslau, 2001; McKnightEily et al., 2011). There also is some evidence to suggest that the impact of insufficient sleep on emotional distress is more pronounced at the extreme levels of short sleep. For example, a study that assessed suicidality among United States high school students found that students who reported short ( $\leq 5$ hours) total sleep times evidenced significantly higher rates of suicidality compared with peers receiving eight hours of sleep, even after controlling for confounding variables such as age, sex, feelings of sadness, and substance abuse (Fitzgerald, Messias, \& Buysse, 2011).

\section{Adolescent Substance Use and Sleep}

As adolescents age, there is an increased risk for experimenting with substance use (Kroutil, Colliver, \& Gfroerer, 2010). There also is evidence to suggest that adolescent sleep patterns and duration predict cigarette, alcohol, and marijuana use (Pasch, Latimer, Cance, Moe, \& Lytle, 2012). As a stimulant, nicotine has been shown to decrease total sleep time and increase sleep latency (Gromov \& Gromov, 2009). In a longitudinal evaluation of sleep patterns and cigarette smoking in a sample of 7960 adolescents, results showed that smokers at baseline (15 years of age) who did not report sleep problems were significantly more likely to have shorter duration of sleep at the 4-year follow-up

than adolescents who never smoked or were noncurrent smokers at follow-up (Patten, Choi, Gillin, \& Pierce, 2000). Similarly, studies suggest that adolescent smokers experience sleep problems including difficulty falling asleep and

getting insufficient sleep on a more frequent

basis as compared to nonsmokers (Holmen,

Barrett-Connor, Holmen, \& Bjermer, 2000; McKnight-Eily et al., 2011; Ohida et al., 2004).

As an endogenous cannabinoid, marijuana use is hypothesized to promote sleep, mostly through reduced arousal (Murillo-Rodriguez, Blanco-Centurion, Sanchez, Piomelli, \& Shiromani, 2003; Schierenbeck et al., 2008). However, evidence among adolescents has been mixed. For example, longitudinal data have 
shown marijuana use to be predictive of increased weekend sleep and weekend oversleep (Pasch et al., 2012), whereas other data indicate that marijuana use is associated with insufficient sleep (McKnight-Eily et al., 2011).

Insufficient sleep, difficulties staying asleep, daytime sleepiness, and early waking have been associated with the use of alcohol in a doseresponse manner (Fernando, Samaranayake, Blank, Roberts, \& Arroll, 2013; Popovici \& French, 2013). An analysis of the association between alcohol consumption and sleep behaviors using data from the National Longitudinal Study of Adolescent Health $(N=14,089)$ revealed that increased consumption of alcohol significantly predicted sleep problems, including trouble falling and staying asleep and sleep apnea among males (Popovici \& French, 2013). Higher rates of alcohol consumption in the past month also have been correlated with lower amounts of weekday sleep (Pasch, Laska, Lytle, \& Moe, 2010).

\section{Sleep Research in Geographic Contexts}

Although previous studies have documented the associations between sleep problems and various risky behaviors in adolescents (McKnightEily et al., 2011; O’Brien \& Mindell, 2005; Wolfson \& Carskadon, 1998), a notable limitation of this research is that participants in these studies were from national samples or suburban locations, thus limiting the generalizability of findings to more discrete geographic areas such as students attending schools in rural areas. For example, McKnight-Eily and colleagues (2011) used a dataset weighted to be representative of adolescents nationally to examine associations between sleep and health risk factors. Though the authors did examine differences in associations based on gender and race/ethnicity, they did not separate students by geographic setting. O'Brien and Mindell (2005) examined associations between adolescents' sleep problems (oversleeping or trouble waking up) and risky behaviors. Two-thirds of participants in the study attended suburban high schools, but the authors did not investigate differences between these participants and participants attending nonsuburban high schools.

\section{Focus on Rural Populations}

Although limited in quantity and scope, the extant literature suggests significant sleep deficits exist among adolescents in rural areas. In a qualitative study of mildly depressed adolescents in rural Pennsylvania, lack of sleep emerged as a stable theme across 10 group interviews (Puskar, Sereika, \& Tusaie-Mumford, 2003). A study of Icelandic teenagers showed small rural-urban differences in total sleep, with rural adolescents getting slightly more sleep on weekdays and slightly less sleep on weekends (Thorleifsdottir, Björnsson, Benediktsdottir, Gislason, \& Kristbjarnarson, 2002). However, we are not aware of any existing studies that have employed quantitative methodologies to specifically examine short sleep duration as a risk factor among rural adolescents living in the United States.

Focused investigations of sleep duration and risk factors among rural youth is important because these students compromise a sizable proportion of the United States educational system. One in four American students attend school in a rural community, one in three American schools are located in rural areas, and more than one half of all school districts are classified as rural by the U.S. Department of Education (National Center for Education Statistics, 2010). Notably, enrollment in rural schools is increasing faster than other geographic locations. For example, although enrollment trends at urban and suburban schools remained generally static from 2006 to 2009, rural schools experienced an eight percent increase during the same timeframe (National Center for Education Statistics, 2009).

Studies that focus on the physical and mental health of rural adolescents also are important given that these individuals are at greater risk of death from unintentional injuries and suicide as compared with urban and suburban populations (Eberhardt \& Pamuk, 2004; Hirsch, 2006). Further research has found an elevated risk of alcohol, tobacco, and illicit substance use in rural adolescents as compared with adolescents living in suburban and urban areas (Atav \& Spencer, 2002). Therefore, there is a compelling need to conduct studies that examine adolescents living in specific geographical contexts. 


\section{Sleep Research in Developmental Contexts}

Because adolescence represents a period of marked physical and psychosocial changes, studies are needed that critically examine unique developmental influences on sleep patterns and the potential correlates with emotional and behavioral functioning. However, few studies have considered developmental factors explicitly. Findings from several investigations demonstrate that total sleep time during the week and on the weekend decreases as students move from the lower to upper grades in high school (Basch et al., 2014; O'Brien \& Mindell, 2005; Yang, Kim, Patel, \& Lee, 2005). At the same time that sleep is decreasing across the adolescent age range, the prevalence rate of depression is increasing by age such that older adolescents have higher rates of depression relative to early adolescents (U.S. Department of Health and Human Services, Substance Abuse and Mental Health Services Administration, 2008). Similar to depression, late adolescents (15-18 years) have higher rates of suicide and suicidal behavior as compared with early adolescents (10-14 years; Mulye et al., 2009). In addition, adolescents in the upper grades (11th and 12th) engage in a higher prevalence of risky and dangerous behaviors such as substance use relative to students in the lower grades (9th and 10th; Kann et al., 2000; O'Brien \& Mindell, 2005). When considered together, it appears plausible that associations between sleep and mental health problems, suicidal behavior, and substance use could vary across grade levels. Therefore, this study sought to contribute to the existing literature by applying a developmental focus to the study of sleep and risk factors across lower and upper grade levels in rural high schools.

\section{Primary Aims}

One of the aims of this study was to examine the proportion of rural adolescents reporting short sleep duration ( $\leq 6$ hours on a typical school night). This study also explored the associations between short sleep duration and mental health, suicidal behaviors, and current substance use among a sample of high school adolescents attending schools in rural areas. We also investigated the impact of development, as evidenced by grade level (9th and 10th vs. 11th and 12 th), on the association between the variables of interest. To our knowledge, no prior studies have specifically examined the association between short sleep duration and risky behaviors in rural adolescent students living in the United States. Given the relative lack of guidance from past literature, no a priori hypotheses were formulated, and therefore the study was considered exploratory in nature.

\section{Method}

\section{Participants}

Complete responses to the sleep and grade level item examined in this study resulted in available data for 987 students from two rural counties in North Carolina. Using Rural-Urban Continuum Codes formulated by the United States Department of Agriculture Economic Research Service (2003), both North Carolina counties were classified under the most rural designation (Code 9; nonmetropolitan county with less than 2,500 inhabitants in an urban cluster, not adjacent to a metropolitan area). The Youth Risk Behavior Survey (YRBS) assesses student race/ethnicity with two questions: (a) "Are you Hispanic or Latino?" (response options are "yes" or "no"); and (b) "What is your race?" (response options are "American Indian or Alaska Native," "Asian," "black or African American," "Native Hawaiian or other Pacific Islander," or "white"). In the current study, approximately $51.9 \%$ were female and $10.5 \%$ were Hispanic or Latino. The majority of students reported their race as White $(86 \%)$, with much smaller proportions describing themselves as American Indian or Alaska Native (2.6\%), Native Hawaiian or Other Pacific Islander (1.8\%), Black or African American $(1.5 \%)$. Less than $1 \%$ of the sample reported their race as Asian or multiethnic, and 7.2\% did not respond to the question. Most of the sample reported the expected age for their grade level; $95.5 \%$ of 9 th grade students reported their ages as 14 or 15 years old, $92.9 \%$ of 10 th grade students reported their ages as 15 or 16 years old, $95.5 \%$ of 11 th grade students reported their ages as 16 or 17 years old, and $98.8 \%$ of 12 th grade students reported their ages as 17 years or older. 


\section{Instrument}

This study used data from the YRBS. Developed by the Centers for Disease Control and Prevention (CDC), the YRBS is a school-based survey designed for students in Grades 9 through 12 in both private and public high schools. The YRBS assesses the prevalence of adolescent behaviors associated with the leading causes of morbidity and mortality in this age cohort. Response items examined in the current study included questions assessing demographic characteristics, self-reported sleep duration on a typical school night, and mental health and substance use behaviors. Further details regarding the YRBS (study design, reliability and validity) have been previously reported (Brener et al., 2013).

\section{Measures}

Sleep duration. Sleep duration was assessed with the question, "On an average school night, how many hours of sleep do you get?" Response options were as follows: "4 or less hours," "5 hours," "6 hours," "7 hours," "8 hours," "9 hours," and "10 or more hours." Responses were dichotomized into 2 variables: longer sleep duration ( 7 or more hours on a typical school night) or short sleep duration (6 or less hours on a typical school night). One of the methodological challenges in determining dichotomous categories for sleep duration is the lack of an evidence-based definition of insufficient sleep in the adolescent population. Although 8 or more hours of sleep per night is commonly recommended for adolescents (National Sleep Foundation, 2006), sleep patterns and duration change throughout adolescence (Pasch et al., 2012), and there are significant differences between sleep duration on school nights relative to weekend nights (Yang et al., 2005). In addition, there is variability in the literature as to what constitutes insufficient sleep. For example, some sleep researchers and experts have defined insufficient sleep as 8 or less hours (McKnight-Eily et al., 2011), others have used 7 hours or less as a cut-off (Eaton et al., 2010), and yet others have used 6 or less per night to quantify sleep deprivation (Roberts \& Duong, 2014). Despite the variability in defining short sleep duration, there is some evidence to suggest the negative consequences of insuf- ficient sleep are only demonstrated at the more extreme ranges (Glozier et al., 2010). In accordance with previous studies, we used 6 hours or less on a typical school night as the cut off for short sleep duration (Angold et al., 2012; Fredriksen, Rhodes, Reddy, \& Way, 2004; Gau \& Soong, 1995; Roberts \& Duong, 2014).

Mental health and suicidal behavior. Participants responded to the following questions related to depression and suicide during the past 12 months using a dichotomous (yes/ no) response scale: did you ever feel so sad or hopeless almost every day for two weeks in a row that you stopped doing some usual activities?; did you ever seriously consider attempting suicide?; did you make a plan about how you would attempt suicide?; and, if you attempted suicide during the past 12 months, did any attempt result in an injury, poisoning, or overdose that had to be treated by a doctor or a nurse? Suicide attempt was assessed with the following question: during the past 12 months, how many times did you actually attempt suicide? Five response options are available for this item, including 0 times, 1 time, 2 or 3 times, 4 or 5 times, 6 or more times. Students who endorsed attempting suicide 1 or more times were considered to have attempted suicide in the past 12 months.

Current substance use. Current substance use behaviors, conceptualized as use within the last 30 days, were assessed with the following questions: on how many days did you have at least one drink of alcohol?; on how many days did you smoke cigarettes?; how many times did you use marijuana? Students who reported using the substance on one or more days (alcohol, cigarettes) or one or more times (marijuana) within the last 30 days were identified as current users of the assessed substance.

\section{Procedure}

The YRBS was administered to students in 9th through 12th grades in two high schools in two rural North Carolina counties in the spring of 2012, resulting in data for 1004 students. School start time for the two high schools was 8:00am and 8:20am, respectively. Data from 17 students were removed because of incomplete responses. Although the students in these schools were overwhelmingly White, significant economic diversity exists within the 
schools. The pooled proportion of students in the two high schools eligible for free or reduced lunch was $51.5 \%$ (U.S. Department of Education, Office of Planning, Evaluation and Policy Development, Performance Information Management Service, 2012). Student participation was anonymous and voluntary, and parental permission was obtained in accord with local regulations. Trained personnel from the regional health department administered the surveys during regular class periods. In terms of response rates, $78 \%$ of students enrolled in these schools participated in the survey. The protocol for the YRBS was approved by the CDC's institutional review board. In addition, these secondary analyses were reviewed and approved by the institutional review board at the investigators' home institutions.

\section{Data Analyses}

All analyses were performed using IBM SPSS Statistics version 22 (IBM Corp., 2013). Prevalence estimates and 95\% confidence intervals (CIs) were calculated for sleep categories (insufficient vs. sufficient). Chi-square analyses were performed to evaluate the association between short and longer sleep duration on each mental health and substance use variable. Additionally, chi-square analyses were used to evaluate differences in likelihood of endorsing risk factors between lower grade level and upper grade level high school students based upon reported sleep duration. Odds ratios (ORs) and 95\% confidence intervals were calculated to examine the significance of the associations between sleep categories and these risky behaviors.

\section{Results}

Overall, $40.2 \%(n=397)$ of the sample reported sleeping six or fewer hours on an average school night. There was no difference between 9th and 10th and 11th and 12th grade students in the likelihood of reporting six or fewer hours of sleep, $\chi^{2}(1, N=987)=1.55, p=.24$. Descriptive statistics regarding frequencies of endorsing mental health, suicidal behavior, and substance use risk factors by grade level categories (lower and upper) are presented in Table 1.

Comparisons between lower and upper grade level students reporting shorter and longer sleep duration are presented in Table 2. Overall, differences in the endorsement of risk factors be-

Table 1

Percentages Reporting Mental Health and Substance Use Risk Factors by Grade Level Grouping

\begin{tabular}{|c|c|c|}
\hline Grade level grouping & $\begin{array}{c}\text { Six or fewer hours (9th through } \\
\text { 10th } n=216-221 ; 11 \text { th } \\
\text { through } 12 \text { th } n=172-176)\end{array}$ & $\begin{array}{c}\text { Seven hours or more (9th through } \\
\text { 10th } n=348-352 ; 11 \text { th through } \\
12 \text { th } n=235-238)\end{array}$ \\
\hline \multicolumn{3}{|l|}{ 9th through 10 th grade } \\
\hline Sad for two weeks & $31.3 \%$ & $18.7 \%$ \\
\hline Suicidal thoughts & $23.6 \%$ & $13.2 \%$ \\
\hline Suicide plan & $24.7 \%$ & $12.1 \%$ \\
\hline Suicide attempt & $25.7 \%$ & $14.2 \%$ \\
\hline Suicide attempt/treatment & $17.4 \%$ & $9.9 \%$ \\
\hline Alcohol last 30 days & $39.8 \%$ & $26.4 \%$ \\
\hline Tobacco last 30 days & $34.4 \%$ & $19.6 \%$ \\
\hline Marijuana last 30 days & $21.8 \%$ & $13.4 \%$ \\
\hline \multicolumn{3}{|l|}{11 th through 12 th grade } \\
\hline Sad for two weeks & $28.9 \%$ & $20.7 \%$ \\
\hline Suicidal thoughts & $16.0 \%$ & $9.8 \%$ \\
\hline Suicide plan & $14.0 \%$ & $9.7 \%$ \\
\hline Suicide attempt & $16.6 \%$ & $9.7 \%$ \\
\hline Suicide attempt/treatment & $9.7 \%$ & $6.7 \%$ \\
\hline Alcohol last 30 days & $51.7 \%$ & $41.2 \%$ \\
\hline Tobacco last 30 days & $44.3 \%$ & $30.7 \%$ \\
\hline Marijuana last 30 days & $25.7 \%$ & $17.6 \%$ \\
\hline
\end{tabular}

Note. The range in sample sizes across grade levels is attributable to variability in the number of respondents who answered the various health-risk questions on the YRBS. 
Table 2

Comparisons of Risk Factor Reporting Frequencies Between Students Reporting $<7$ Hours and $\geq 7$ Hours of Sleep Per School Night

\begin{tabular}{|c|c|c|c|c|c|}
\hline Grade level grouping & $N$ & $\begin{array}{l}\text { Chi-square } \\
(d f=1)\end{array}$ & Sig. & OR & $95 \% \mathrm{CI}$ \\
\hline \multicolumn{6}{|l|}{ 9th through 10th grade } \\
\hline Sad for two weeks & 565 & 11.90 & .001 & 1.98 & $1.34-2.94$ \\
\hline Suicidal thoughts & 565 & 10.21 & .002 & 2.04 & $1.31-3.16$ \\
\hline Suicide plan & 567 & 15.15 & .001 & 2.38 & $1.52-3.72$ \\
\hline Suicide attempt & 570 & 11.73 & .001 & 2.09 & $1.36-3.19$ \\
\hline Suicide attempt/treatment & 570 & 6.76 & .01 & 1.91 & $1.17-3.13$ \\
\hline Alcohol last 30 days & 573 & 11.28 & .001 & 1.84 & $1.29-2.64$ \\
\hline Tobacco last 30 days & 573 & 15.71 & .001 & 2.15 & $1.47-3.15$ \\
\hline Marijuana last 30 days & 572 & 7.01 & .01 & 1.81 & $1.16-2.82$ \\
\hline \multicolumn{6}{|l|}{ 11th through 12th grade } \\
\hline Sad for two weeks & 410 & 3.70 & .06 & 1.56 & $0.99-2.46$ \\
\hline Suicidal thoughts & 410 & 3.56 & .07 & 1.75 & $0.97-3.16$ \\
\hline Suicide plan & 408 & 1.73 & .21 & 1.50 & $0.82-2.76$ \\
\hline Suicide attempt & 413 & 4.37 & .05 & 1.86 & $1.03-3.33$ \\
\hline Suicide attempt/treatment & 413 & 1.23 & .28 & 1.49 & $0.73-3.04$ \\
\hline Alcohol last 30 days & 414 & 4.52 & .05 & 1.53 & $1.03-2.26$ \\
\hline Tobacco last 30 days & 414 & 8.13 & .01 & 1.80 & $1.20-2.70$ \\
\hline Marijuana last 30 days & 413 & 3.95 & .05 & 1.62 & $1.00-2.60$ \\
\hline
\end{tabular}

Note. Odds ratios calculated using the $\geq 7$ hours groups as the referent.

tween students reporting shorter sleep duration and longer sleep duration were most pronounced among 9th and 10th graders. Rural 9th and 10th grade students reporting 6 or fewer hours of sleep were more likely to endorse each of the mental health, suicidal behavior, and substance use items examined. However, significant differences emerged between sleep groups on only suicide attempts and alcohol, tobacco, and marijuana use for 11th and 12th grade students. Furthermore, the magnitude of relative odds between the sleep groups was greater across all risk factors in the lower grade level students than the upper grade level students.

Chi-square analyses indicate that lower grade level students with short sleep durations were more likely than upper grade level students with short sleep durations to report a suicide plan over the past year, $\chi^{2}(1, n=391)=6.91, p=$ $.01, O R=2.02,95 \%$ CI $[1.19,3.42]$, report a suicide attempt over the past year, $\chi^{2}(1, n=$ $393)=4.76, p<.05, O R=1.74,95 \% \mathrm{CI}$ $[1.05,2.87]$, and report a suicide attempt requiring medical treatment, $\chi^{2}(1, n=397)=4.07$, $p=.05, O R=1.96,95 \%$ CI $[1.07,3.61]$.

Lower grade level students reporting short sleep durations were less likely than their upper grade level counterparts to report tobacco use, $\chi^{2}(1, n=393)=4.76, p<.05, O R=1.74$, $95 \%$ CI [1.05, 2.87], and alcohol use, $\chi^{2}(1, n=$ $393)=5.59, p<.05, O R=0.62,95 \% \mathrm{CI}$ $[0.41,0.92]$. No differences between upper grade level and lower grade level students reporting short sleep durations emerged in likelihood of reporting depressive symptoms or thoughts of suicide.

Among students reporting longer sleep durations, lower grade level students were less likely to report tobacco use, $\chi^{2}(1, n=590)=9.52$, $p<.01, O R=0.55,95 \%$ CI $[0.38,0.81]$, and alcohol use, $\chi^{2}(1, n=590)=14.12, p<.01$, $O R=0.51,95 \%$ CI $[0.36,0.73]$. No age-based differences among students reporting longer sleep durations emerged in likelihood of reporting marijuana use or depression or suicide risk factors.

\section{Discussion}

The purpose of this study was to expand on previous methodologies by investigating the impact of sleep duration in previously neglected geographic and developmental contexts. To our knowledge, this is the first study to directly examine the association between sleep duration and mental health and substance use risk factors 
among rural American high school students. The main and novel results from this study begin with the finding that $40 \%$ of the sample reported sleeping six or fewer hours per night. From a developmental perspective, lower grade level students who reported short sleep duration had significantly higher levels of suicide-related behaviors than the upper grade level sleep deprived adolescents. Consistent with prior research that demonstrates increased risk for substance use as adolescents age (Kroutil et al., 2010), tobacco and alcohol use were significantly more prevalent among upper grade level students of both longer and shorter sleep duration as compared to their peers in the lower grade level. Together these data add to our current understanding of the severity of the short sleep duration problem among rural youth as well as the implications for other risk behaviors including suicidality.

Our data showing that $40 \%$ of rural students sleep six or fewer hours on typical school nights are consistent with results from a study that found $40 \%$ of a nationally representative sample of high school students getting 6 or fewer hours of sleep per school night (Basch et al., 2014). By contrast, other studies have reported about one fourth $(\sim 25 \%)$ of adolescents from metropolitan and suburban areas sleeping 6 or less hours per night (Roberts \& Duong, 2014; Roberts, Roberts, \& Xing, 2011; Wolfson \& Carskadon, 1998). One potential explanation for the higher prevalence rate of shorter sleep duration among students in rural areas is that these adolescents are more likely to travel substantial distances to reach school and also report rougher rides (Howley, Howley, \& Shamblen, 2001), necessitating earlier waking times and potentially fewer opportunities for sleep on these rides (Purcell \& Shackelford, 2005).

Results also indicate robust associations exist between mental health and substance abuse risk factors and short sleep duration in high school students residing in rural settings. The rate of students endorsing suicide attempts in the current sample is more than twice the national rate, and the rate of students reporting attempts requiring medical treatment factors in the sample is nearly five times the national rate (Kann et al., 2014). The findings converge with a growing body of literature demonstrating the association between insufficient sleep and risky behaviors (e.g., suicidal ideation and substance abuse;
O'Brien \& Mindell, 2005), while extending the generalizability of this work to rural areas specifically. Of particular concern is the strong relationship between short sleep duration and suicidal behaviors in these students given the high rates of completed suicides among youth in rural areas (Armstrong \& Manion, 2006; State and Territorial Injury Prevention Directors Association Rural Youth Suicide Prevention Workgroup, 2008). Almost one in three lower grade level students reporting six or fewer hours of sleep also reported symptoms of depression, and more than one in six of these students reported a suicide attempt necessitating medical treatment. The strength of these observed relationships suggests that sleep hygiene could be an important consideration in universal youth suicide prevention efforts delivered in rural schools and communities.

From a developmental perspective, these data show that sleep-deprived students in the lower grades demonstrated a higher prevalence of suicide-related risk factors relative to students in the upper grade levels. These differences did not emerge in prevalence rates between lower grade level and upper grade level students getting longer duration of sleep. This finding is surprising given prior research that demonstrated that adolescents in the upper grades engage in a higher prevalence of suicidal behaviors relative to students in the lower grade levels (Kann et al., 2000; O’Brien \& Mindell, 2005). It is notable, though, that these studies did not directly analyze the associations between sleep, mental health, and risky behaviors across developmental levels. One potential explanation for this result is that the psychosocial and academic challenges associated with the developmental milestone of transitioning from middle school to high school (Newman, Newman, Griffen, O'Connor, \& Spas, 2007) confers additional risk for mental health and behavioral problems in the context of sleep deprivation. Because high school start times are frequently earlier than middle school start times, adolescents may experience significant adjustment problems to the earlier school schedule (Carskadon, Wolfson, Acebo, Tzischinsky, \& Seifer, 1998). Thus, although older adolescents may be more likely to engage in risk-taking behaviors (Kann et al., 2000; O'Brien \& Mindell, 2005), our findings suggest that sleep deprivation may have an even greater adverse impact on suicidal behaviors for 
students in the early high school grades. On the other hand, differential prevalence rates among the risk factors by grade level also may be partially accounted for by attrition in the upper grade levels. For example, it is possible that students who dropped out in the upper grades also may be the very ones who had problems with mental health and substance use.

Results from this investigation have important clinical and policy implications for rural communities and schools. Sleep deprivation among adolescents is a significant public health problem that, regardless of geographic location, occurs at alarmingly high rates. School-based health centers (SBHC) and school mental health $(\mathrm{SMH})$ programs represent feasible and responsive approaches to addressing co-occurring problems of sleep deprivation and mental health ailments among rural adolescents (Guo, Wade, \& Keller, 2008; Mason-Jones et al., 2012; Michael, Renkert, Wandler, \& Stamey, 2009; Owens, Watabe, \& Michael, 2013). Such programs have been demonstrated to be effective in the provision of high quality health care and mental health services provided at no cost to youth and families and have been shown to be effective at ameliorating psychological distress among rural adolescents (Albright et al., 2013). Similarly, medical homes with care coordination and community health clinics that colocate mental health services represent promising approaches for improving access and availability to behavioral health services in rural areas (Miller, Petterson, Burke, Phillips, \& Green, 2014). The data from the present study suggest that clinicians in these settings should be aware of the potential consequences of short weekday sleep duration. At the preventative screening level, these clinics could include items on routine screening questionnaires that evaluate sleep duration and hygiene. These items may be perceived by adolescents as less threatening or stigmatizing than more direct questions about depression and suicide that are more typical of universal screeners. Because stigma among children and adolescents poses a significant barrier to assessment and treatment of mental health concerns (Wahl, 2002), the inclusion of sleep questions also may improve the sensitivity of screening tools.

Lower grade level high school students who report significant sleep issues and no other mental health or substance use risk factors also may be targeted by community and school clinic programs for early intervention, as some have suggested that treating insomnia could prevent the development of future depressive episodes and substance abuse (Roane \& Taylor, 2008). Interventions evidenced to be effective for insomnia in adolescents (e.g., Cognitive Behavioral Therapy for Insomnia; Bootzin \& Stevens, 2005; Clarke \& Harvey, 2012) are typically less intensive than cognitive-behavioral therapy (CBT) interventions for depression and substance use. Other new CBT-based sleep interventions that show promise are group-based or delivered via the Internet (de Bruin, Oort, Bogels, \& Meijer, 2014). Thus, selective interventions for sleep deprivation could be an efficient endeavor for rural behavioral health programs with limited resources.

For adolescents presenting with mental health concerns such as depression and substance use, incorporating sleep hygiene interventions into existing treatment protocols may produce better results. Studies have suggested that the treatment of co-occurring sleep problems can result in significant improvements in depressive symptoms and substance use (Bootzin \& Stevens, 2005; Dewald-Kaufmann, Oort, \& Meijer, 2014). Additionally, Thase and colleagues (1996) found that individuals with abnormal sleep profiles were relatively less responsive to CBT for depression, and Watanabe et al. (2011) found that adding behavior therapy for insomnia to a treatment protocol for residual depression resulted in more positive outcomes. Therefore, the assessment and consideration of sleep problems is recommended as a matter of course in behavioral health clinics located in rural areas.

From a policy standpoint, these data suggest the possibility that rural students may be likely to benefit from delaying school start times given the high prevalence of short sleep duration. There is a compelling literature that attests to the impact of puberty on circadian rhythms that results in a sleep phase delay (Roenneberg et al., 2004, 2007). In addition, youth who are sleep deprived during the school week are prone to compensate for the sleep debt on weekends which can then influence well-being and consumption of substances (e.g., caffeine, nicotine, and alcohol) (Wittmann, Dinich, Merrow, \& Roenneberg, 2006). Moreover, and specific to rural areas, adolescent male students that have 
to travel long distances to school are at increased risk factor for suicidal ideation (Armstrong \& Manion, 2006). These findings high-light the importance of aligning school start times to better match student sleep schedules. In a study that examined sleep duration and phys-ical and mental health outcomes after delaying the start time of a school in Rhode Island by 30 minutes, sleep time on school nights increased by 45 minutes and the percentage of students reporting less than seven hours of sleep per night decreased by nearly $80 \%$ (Owens, Belon, \& Moss, 2010). In

addition, students reported reduced daytime sleepiness as well as feeling less fatigued and depressed. Another recent study that examined

later school start time in adolescents found significant improvements in sleep duration, daytime sleepiness, mood, and caffeine use (Boergers, Gable, \& Owens, 2014). Although delaying high school start times was recently recommended by the American Academy of Pediatrics (Owens et al., 2014) and is a proven strategy for lengthening sleep duration among adolescents (Wahlstrom, 2002), it clearly represents a major system shift that may not be feasible, practical, or even warranted. Because of these challenges, some experts have suggested that delaying school start times does not need to occur at a universal level (Owens et

al., 2010). In school districts where delayed school start times may not be a plausible policylevel prevention approach, research points to the efficacy of earlier bedtimes, particularly during

the academic year, as a wellness promot-ing strategy among youth. For example, one notable study from this area comes from an analysis of the National Longitudinal Study of Adolescent Health data, which showed that in a sample of high school students, late school year bedtime was predictive of poorer academic per-formance and increased levels of emotional dis-tress up to eight years later (Asarnow, McGlinchey,

\& Harvey, 2014), and this associ-ation was independent of the total hours of sleep. Thus, efforts to partner with parents and caretakers to

promote earlier bedtime, particu-larly in the middle school and lower high school grade level years, could potentially improve ac-ademic and mental health indices across time. To be successful, such efforts should be tailored to fit the needs of rural communities, as travel times between school, home, and other activi- ties may be a significant barrier to planning earlier bedtimes.

There are several notable limitations to the study design. As with all cross-sectional data, causality cannot be inferred among sleep, mental health, and risk-taking behaviors. The reliance on a single-item to assess sleep may be considered less reliable than using multiple subjective and objective assessment measures such as wrist-actigraphy, sleep diaries, or laboratorybased polysomnography. Nonetheless, the use of a single sleep item has been employed in previous research efforts (Culnan, Holiday Brooks, Daly, Aggarwal, \& Kloss, 2013; Eaton et al., 2010; Hildenbrand et al., 2013; McKnight-Eily et al., 2011), and previous studies have confirmed strong correlations between physiological and self-report assessments of sleep (Roberts et al., 2001). The sleep item only assessed duration and not other important indicators of health outcomes such as quality of sleep. For example, poor sleep quality, including measures of sleep latency, is associated with elevated psychological distress and comorbid physical health disorders and illnesses (Scott, Paterson, \& Happell, 2014). Poor sleep quality in childhood also has been associated with increased risk of depression in adulthood (Greene, Gregory, Fone, \& White, 2015) It also is worth noting that there is some inconsistency in the phrasing of the substance use questions on the YRBS. For example, the questions for alcohol and cigarette use query about number of days of use per month whereas the question about marijuana use asks about number of times of use per month. This difference should be considered in the context of the current results.

Because the current study relied on selfreport responses for the variables of interest, the extent of underreporting or overreporting of certain behaviors cannot be accurately determined. However, previous research has confirmed that youth self-report is reliable and valid for identifying sleep duration (Meltzer et al., 2013; Werner, Molinari, Guyer, \& Jenni, 2008; Wolfson et al., 2003). In addition, before completing the survey, students are informed that their answers are anonymous and their privacy will be protected. Internal reliability checks also are run to identify responses with logical inconsistencies or students who falsify their answers and when this occurs the data are removed from the final dataset (Brener et al., 2013). Moreover, 
psychometric analysis of the methodology of the 1991 and 1999 YRBS has revealed strong test-retest reliability (Brener et al., 2004). The data used in the analyses only represent students present in school at the time of the survey. Therefore, findings may not be representative of students absent the day of survey administration or students that dropped out of school. In addition, our sample was drawn from high schools composed of Grades 9 through 12. Although the preponderance of rural high schools are composed of these grade levels (National Center for Educational Statistics, 1997), some schools include fewer (e.g., Grades 10 through 12) or more grade levels (e.g., 7th through 12th grade). Another limitation of the current study was the use of grade level to examine developmental differences in the variables of interest. Although expected age ranges were found in each grade level, we cannot rule out the possibility that the overlap in age ranges between grades impacted the results. Finally, because the rural sample was drawn from a limited geographic area, the results may not generalize to all rural areas. Of particular concern is the relative homogeneity of race and ethnicity in the sample.

In conclusion, sleep deprivation among adolescents is prevalent and represents a significant public health problem given the importance of adequate sleep to cognition (memory, attention), emotional well-being, and overall physical health (for a review, see Owens et al., 2014). The causes of sleep deprivation are many and include environmental and behavioral factors that influence teenage sleep patterns. Addressing the complex challenge of short sleep duration requires a multilevel approach that includes clinical and policy-level strategies. At the universal level, screening efforts conducted in school-based settings are needed to identify rural students experiencing chronic sleep deprivation. Sleep interventions delivered in health education classes during the early grades of high school may prove especially useful as lower grade level students adjust to the new start time and increased academic demands associated with high school. At the selective and indicated level, clinicians working in SBHC and SMH programs can provide individualized, evidencebased interventions to students presenting with sleep problems. From a research standpoint, longitudinal studies are needed to better understand the impact of sleep deprivation in rural populations and to further the evidence-base around the development and implementation of targeted interventions that match the needs of these students. Therefore, future research should seek to disentangle the associations between these variables and sleep length while also acknowledging that sleep is a complex behavior impacted by both biological and environmental determinants (Zisapel, 2007).

\section{References}

Albright, A., Michael, K. D., Massey, C. S., Sale, R., Kirk, A., \& Egan, T. E. (2013). An evaluation of an interdisciplinary rural school mental health program in Appalachia. Advances in School Mental Health Promotion, 6, 189-202. http://dx.doi.org/ 10.1080/1754730X.2013.808890

Angold, A., Erkanli, A., Copeland, W., Goodman, R., Fisher, P. W., \& Costello, E. J. (2012). Psychiatric diagnostic interviews for children and adolescents: A comparative study. Journal of the American Academy of Child \& Adolescent Psychiatry, 51, 506-517. http://dx.doi.org/10.1016/j.jaac.2012.02 .020

Armstrong, L. L., \& Manion, I. G. (2006). Suicidal ideation in young males living in rural communities: Distance from school as a risk factor, youth engagement as a protective factor. Vulnerable Children and Youth Studies, 1, 102-113. http:// dx .doi.org/10.1080/17450120600659010

Asarnow, L. D., McGlinchey, E., \& Harvey, A. G. (2014). The effects of bedtime and sleep duration on academic and emotional outcomes in a nationally representative sample of adolescents. Journal of Adolescent Health, 54, 350-356. http:// dx.doi .org/10.1016/j.jadohealth.2013.09.004

Atav, S., \& Spencer, G. A. (2002). Health risk behaviors among adolescents attending rural, suburban, and urban schools: A comparative study. Family \& Community Health, 25, 53-64. http:// dx .doi.org/10.1097/00003727-200207000-00007

Basch, C. E., Basch, C. H., Ruggles, K. V., \& Rajan, S. (2014). Prevalence of sleep duration on an average school night among 4 nationally representative successive samples of American high school students, 2007-2013. Preventing Chronic Disease, 11, E216. http://dx.doi.org/10.5888/pcd11.140383

Boergers, J., Gable, C. J., \& Owens, J. A. (2014). Later school start time is associated with improved sleep and daytime functioning in adolescents. Journal of Developmental and Behavioral Pediatrics, 35, 11-17. http://dx.doi.org/10.1097/DBP .0000000000000018

Bootzin, R. R., \& Stevens, S. J. (2005). Adolescents, substance abuse, and the treatment of insomnia and daytime sleepiness. Clinical Psychology Review, 
25, 629-644. http://dx.doi.org/10.1016/j.cpr.2005 .04 .007

Brener, N. D., Kann, L., Kinchen, S. A., Grunbaum, J. A., Whalen, L., Eaton, D., . . Ross, J. G. (2004). Methodology of the youth risk behavior surveillance system. Morbidity and Mortality Weekly Report, 53, 1-13.

Brener, N. D., Kann, L., Shanklin, S., Kinchen, S., Eaton, D. K., Hawkins, J., \& Flint, K. H., \& the Centers for Disease Control and Prevention. (2013). Methodology of the Youth Risk Behavior Surveillance System-2013. Morbidity and Mortality Weekly Report, 62, 1-20.

Carskadon, M. A., Acebo, C., \& Jenni, O. G. (2004). Regulation of adolescent sleep: Implications for behavior. Annals of the New York Academy of Sciences, 1021, 276-291. http://dx.doi.org/ 10.1196/annals.1308.032

Carskadon, M. A., Wolfson, A. R., Acebo, C., Tzischinsky, O., \& Seifer, R. (1998). Adolescent sleep patterns, circadian timing, and sleepiness at a transition to early school days. Sleep, 21, 871-881.

Clarke, G., \& Harvey, A. G. (2012). The complex role of sleep in adolescent depression. Child and Adolescent Psychiatric Clinics of North America, 21, 385-400. http://dx.doi.org/10.1016/j.chc.2012 .01 .006

Culnan, E., Holiday Brooks, S., Daly, B. P., Aggarwal, R., \& Kloss, J. (2013). Insufficient sleep and weight status among high school students: Should we be focusing on the extremes? Children's Health Care, 42, 99-115. http://dx.doi.org/ 10.1080/02739615.2013.786551

Dahl, R. E., \& Lewin, D. S. (2002). Pathways to adolescent health sleep regulation and behavior. Journal of Adolescent Health, 31, 175-184. http:// dx.doi.org/10.1016/S1054-139X(02)00506-2

de Bruin, E. J., Oort, F. J., Bögels, S. M., \& Meijer, A. M. (2014). Efficacy of internet and groupadministered cognitive behavioral therapy for insomnia in adolescents: A pilot study. Behavioral Sleep Medicine, 12, 235-254. http://dx.doi.org/ 10.1080/15402002.2013.784703

Dewald-Kaufmann, J. F., Oort, F. J., \& Meijer, A. M. (2014). The effects of sleep extension and sleep hygiene advice on sleep and depressive symptoms in adolescents: A randomized controlled trial. Journal of Child Psychology and Psychiatry, 55, 273-283. http://dx.doi.org/10.1111/jcpp.12157

Do, Y. K., Shin, E., Bautista, M. A., \& Foo, K. (2013). The associations between self-reported sleep duration and adolescent health outcomes: What is the role of time spent on Internet use? Sleep Medicine, 14, 195-200. http://dx.doi.org/ 10.1016/j.sleep.2012.09.004

Eaton, D. K., McKnight-Eily, L. R., Lowry, R., Perry, G. S., Presley-Cantrell, L., \& Croft, J. B. (2010). Prevalence of insufficient, borderline, and optimal hours of sleep among high school students - United States, 2007. Journal of Adolescent Health, 46, 399-401. http://dx.doi.org/10.1016/ $\mathrm{j}$.jadohealth.2009.10.011

Eberhardt, M. S., \& Pamuk, E. R. (2004). The importance of place of residence: Examining health in rural and nonrural areas. American Journal of Public Health, 94, 1682-1686. http://dx.doi.org/ 10.2105/AJPH.94.10.1682

Fernando, A. T., Samaranayake, C. B., Blank, C. J., Roberts, G., \& Arroll, B. (2013). Sleep disorders among high school students in New Zealand. Journal of Primary Health Care, 5, 276-282.

Fitzgerald, C. T., Messias, E., \& Buysse, D. J. (2011). Teen sleep and suicidality: Results from the youth risk behavior surveys of 2007 and 2009. Journal of Clinical Sleep Medicine, 7, 351-356.

Fredriksen, K., Rhodes, J., Reddy, R., \& Way, N. (2004). Sleepless in Chicago: Tracking the effects of adolescent sleep loss during the middle school years. Child Development, 75, 84-95. http:// dx.doi .org/10.1111/j.1467-8624.2004.00655.x

Gau, S. F., \& Soong, W. T. (1995). Sleep problems of junior high school students in Taipei. Sleep, 18, 667-673.

Glozier, N., Martiniuk, A., Patton, G., Ivers, R., Li, Q., Hickie, I., . . Stevenson, M. (2010). Short sleep duration in prevalent and persistent psychological distress in young adults: The DRIVE study. Sleep, 33, 1139-1145.

Greene, G., Gregory, A. M., Fone, D., \& White, J. (2015). Childhood sleeping difficulties and depression in adulthood: The 1970 British Cohort Study. Journal of Sleep Research, 24, 19-23. http:// dx .doi.org/10.1111/jsr.12200

Gromov, I., \& Gromov, D. (2009). Sleep and substance use and abuse in adolescents. Child and Adolescent Psychiatric Clinics of North America, 18, 929-946. http://dx.doi.org/10.1016/j.chc.2009 .04 .004

Guo, J. J., Wade, T. J., \& Keller, K. N. (2008). Impact of school-based health centers on students with mental health problems. Public Health Reports, $123,768-780$.

Hildenbrand, A. K., Daly, B. P., Nicholls, E., BrooksHolliday, S., \& Kloss, J. D. (2013). Increased risk for school violence-related behaviors among adolescents with insufficient sleep. The Journal of School Health, 83, 408 - 414. http://dx.doi.org/ 10.1111/josh.12044

Hirsch, J. K. (2006). A review of the literature on rural suicide: Risk and protective factors, incidence, and prevention. Crisis: The Journal of Crisis Intervention and Suicide Prevention, 27, 189199. http://dx.doi.org/10.1027/0227-5910.27.4 .189

Holmen, T. L., Barrett-Connor, E., Holmen, J., \& Bjermer, L. (2000). Health problems in teenage 
daily smokers versus nonsmokers, Norway, 19951997: The Nord-Trøndelag Health Study. American Journal of Epidemiology, 151, 148-155. http://dx.doi.org/10.1093/

oxfordjournals.aje .a010182

Howley, C. B., Howley, A. A., \& Shamblen, S. (2001). Riding the school bus: A comparison of the rural and suburban experience in five states. Journal of Research in Rural Education, 17, 41-63.

IBM Corp. (2013). SPSS statistics for Windows, version 22.0. Armonk, NY: Author.

Johnson, E. O., \& Breslau, N. (2001). Sleep problems and substance use in adolescence. Drug and Alcohol Dependence, 64, 1-7. http://dx.doi.org/ 10.1016/S0376-8716(00)00222-2

Kann, L., Kinchen, S., Shanklin, S. L., Flint, K. H., Kawkins, J., Harris, W. A., . . Z Zaza, S., \& the Centers for Disease Control and Prevention (CDC). (2014). Youth risk behavior surveillanceUnited States, 2013. Morbidity and Mortality Weekly Report, 63, 1-168.

Kann, L., Kinchen, S. A., Williams, B. I., Ross, J. G., Lowry, R., Grunbaum, J. A., \& Kolbe, L. J. (2000). Youth risk behavior surveillance-U. S., 1999. Morbidity and Mortality Weekly Report, 49, 1-32.

Kroutil, L., Colliver, J., \& Gfroerer, J. (2010). Age and cohort patterns of substance use among adolescents. OAS data review. Rockville, MD: Substance Abuse and Mental Health Services Administration.

Mantz, J., Muzet, A., \& Winter, A. S. (2000). [The characteristics of sleep-wake rhythm in adolescents aged 15-20 years. A survey made at school during ten consecutive days]. Archives of Pediatrics, 7, 256-262. http://dx.doi.org/10.1016/S0929693X(00)88741-2

Mason-Jones, A. J., Crisp, C., Momberg, M., Koech, J., De Koker, P., \& Mathews, C. (2012). A systematic review of the role of school-based healthcare in adolescent sexual, reproductive, and mental health. Systematic Reviews, 1, 49. http:// dx.doi .org/10.1186/2046-4053-1-49

McKnight-Eily, L. R., Eaton, D. K., Lowry, R., Croft, J. B., Presley-Cantrell, L., \& Perry, G. S. (2011). Relationships between hours of sleep and health-risk behaviors in US adolescent students. Preventive Medicine: An International Journal Devoted to Practice and Theory, 53, 271-273. http://dx.doi.org/10.1016/j.ypmed.2011.06.020

Meltzer, L. J., Avis, K. T., Biggs, S., Reynolds, A. C., Crabtree, V. M., \& Bevans, K. B. (2013). The Children's Report of Sleep Patterns (CRSP): A self-report measure of sleep for school-aged children. Journal of Clinical Sleep Medicine, 9, 235245.

Michael, K. D., Renkert, L. E., Wandler, J., \& Stamey, T. (2009). Cultivating a new harvest: Rationale and preliminary results from a growing interdisciplinary rural school mental health program. Advances in School Mental Health Promotion, 2, $40-50$. http://dx.doi.org/10.1080/ 1754730X.2009.9715703

Miller, B. F., Petterson, S., Burke, B. T., Phillips, R. L., Jr., \& Green, L. A. (2014). Proximity of providers: Colocating behavioral health and primary care and the prospects for an integrated workforce. American Psychologist, 69, 443-451. http://dx.doi.org/10.1037/a0036093

Mulye, T. P., Park, M. J., Nelson, C. D., Adams, S. H., Irwin, C. E., Jr., \& Brindis, C. D. (2009). Trends in adolescent and young adult health in the United States. Journal of Adolescent Health, 45, 8-24. http://dx.doi.org/10.1016/j.jadohealth.2009 .03 .013

Murillo-Rodriguez, E., Blanco-Centurion, C., Sanchez, C., Piomelli, D., \& Shiromani, P. J. (2003). Anandamide enhances extracellular levels of adenosine and induces sleep: An in vivo microdialysis study. Sleep, 26, 943-947.

National Center for Educational Statistics. (1997). Statistical analysis report: Characteristics of small and rural school districts. Washington, DC: Author.

National Center for Education Statistics. (2009). Public elementary/secondary school universe survey, 2008-09, Version 1a. Washington, DC: Author.

National Center for Education Statistics. (2010). Common core of data. Retrieved from http://nces. ed.gov/ccd/cddata.asp

National Center for Health Statistics. (2009). The National Survey of Children's Health (NSCH), 2007: The public use data file and documentation. Hyattsville, MD: U. S. Department of Health and Human Services.

National Sleep Foundation. (2006). Adolescent sleep needs and patterns: Research report and resource guide. Retrieved from http://sleepfoundation.org/ sites/default/files/sleep_and_teens_report1.pdf

Newman, B. M., Newman, P. R., Griffen, S., O'Connor, K., \& Spas, J. (2007). The relationship of social support to depressive symptoms during the transition to high school. Adolescence, 42, 441-459.

O’Brien, E. M., \& Mindell, J. A. (2005). Sleep and risk-taking behavior in adolescents. Behavioral Sleep Medicine, 3, 113-133. http://dx.doi.org/ 10.1207/s15402010bsm0303_1

Ohida, T., Osaki, Y., Doi, Y., Tanihata, T., Minowa, M., Suzuki, K., . . . Kaneita, Y. (2004). An epidemiologic study of self-reported sleep problems among Japanese adolescents. Sleep, 27, 978-985.

Owens, J. A., Belon, K., \& Moss, P. (2010). Impact of delaying school start time on adolescent sleep, mood, and behavior. Archives of Pediatrics \& Ad- 
olescent Medicine, 164, 608-614. http://dx.doi .org/10.1001/archpediatrics.2010.96

Owens, J. A., \& the Adolescent Sleep Working Group, \& the Committee on Adolescence, \& the Council on School Health. (2014). School start times for adolescents. Pediatrics, 134, 642-649. http://dx.doi.org/10.1542/peds.2014-1697

Owens, J., Watabe, Y., \& Michael, K. D. (2013). Culturally responsive school mental health in rural communities. In C. S. Clauss-Ehlers, Z. Serpell, \& M. D. Weist (Eds.), Handbook of culturally responsive school mental health: Advancing research, training, practice, and policy (pp. 31-42). New York, NY: Springer. http://dx.doi.org/ 10.1007/978-1-4614-4948-5_3

Pasch, K. E., Laska, M. N., Lytle, L. A., \& Moe, S. G. (2010). Adolescent sleep, risk behaviors, and depressive symptoms: Are they linked? American Journal of Health Behavior, 34, 237-248. http:// dx.doi.org/10.5993/AJHB.34.2.11

Pasch, K. E., Latimer, L. A., Cance, J. D., Moe, S. G., \& Lytle, L. A. (2012). Longitudinal bi-directional relationships between sleep and youth substance use. Journal of Youth and Adolescence, 41, 1184 1196. http://dx.doi.org/10.1007/s 10964-0129784-5

Patten, C. A., Choi, W. S., Gillin, J. C., \& Pierce, J. P. (2000). Depressive symptoms and cigarette smoking predict development and persistence of sleep problems in US adolescents. Pediatrics, 106, e23. http://dx.doi.org/10.1542/peds.106.2.e23

Popovici, I., \& French, M. T. (2013). Binge drinking and sleep problems among young adults. Drug and Alcohol Dependence, 132, 207-215. http:// dx.doi .org/10.1016/j.drugalcdep.2013.02.001

Purcell, D., \& Shackelford, R. (2005, January). An evaluation of the impact of rural school consolidation: What challenges may a new round of rural school consolidations have on the safety, educational performance, and social environment of rural communities? Presentation to the National $\mathrm{Ru}-$ ral Education Association.

Puskar, K., Sereika, S., \& Tusaie-Mumford, K. (2003). Effect of the Teaching Kids to Cope (TKC) program on outcomes of depression and coping among rural adolescents. Journal of Child and Adolescent Psychiatric Nursing, 16, 71-80. http:// dx.doi.org/10.1111/j.1744-6171.2003.tb00350.x

Roane, B. M., \& Taylor, D. J. (2008). Adolescent insomnia as a risk factor for early adult depression and substance abuse. Sleep, 31, 1351-1356.

Roberts, R. E., \& Duong, H. T. (2014). The prospective association between sleep deprivation and depression among adolescents. Sleep, 37, 239-244.

Roberts, R. E., Roberts, C. R., \& Chen, I. G. (2001). Functioning of adolescents with symptoms of disturbed sleep. Journal of Youth and Adolescence, 30, 1-18. http://dx.doi.org/10.1023/A:1005230820074
Roberts, R. E., Roberts, C. R., \& Xing, Y. (2011). Restricted sleep among adolescents: Prevalence, incidence, persistence, and associated factors. $B e$ havioral Sleep Medicine, 9, 18-30. http:// dx.doi .org/10.1080/15402002.2011.533991

Roenneberg, T., Kuehnle, T., Juda, M., Kantermann, T., Allebrandt, K., Gordijn, M., \& Merrow, M. (2007). Epidemiology of the human circadian clock. Sleep Medicine Reviews, 11, 429-438. http://dx.doi.org/10.1016/j.smrv.2007.07.005

Roenneberg, T., Kuehnle, T., Pramstaller, P. P., Ricken, J., Havel, M., Guth, A., \& Merrow, M. (2004). A marker for the end of adolescence. Current Biology, 14, R1038-R1039. http://dx.doi.org/ 10.1016/j.cub.2004.11.039

Schierenbeck, T., Riemann, D., Berger, M., \& Hornyak, M. (2008). Effect of illicit recreational drugs upon sleep: Cocaine, ecstasy and marijuana. Sleep Medicine Reviews, 12, 381-389. http://dx.doi.org/ 10.1016/j.smrv.2007.12.004

Scott, D., Paterson, J. L., \& Happell, B. (2014). Poor sleep quality in Australian adults with comorbid psychological distress and physical illness. Behavioral Sleep Medicine, 12, 331-341. http:// dx.doi .org/10.1080/15402002.2013.819469

Singh, G. K., \& Kenney, M. K. (2013). Rising prevalence and neighborhood, social, and behavioral determinants of sleep problems in US children and adolescents, 2003-2012. Sleep Disorders, 2013, 394320. http://dx.doi.org/10.1155/2013/394320

State and Territorial Injury Prevention Directors Association Rural Youth Suicide Prevention Group. (2008). Preventing youth suicide in rural America: Recommendations to states. Retrieved from http://www.sprc.org/sites/sprc.org/files/ library/ruralyouth.pdf

Strauch, B. (2003). The primal teen. New York, NY: Doubleday.

Thase, M. E., Simons, A. D., \& Reynolds, C. F., III (1996). Abnormal electroencephalographic sleep profiles in major depression: Association with response to cognitive behavior therapy. Archives of General Psychiatry, 53, 99-108. http://dx.doi.org/ 10.1001/archpsyc.1996.01830020013003

Thorleifsdottir, B., Björnsson, J. K., Benediktsdottir, B., Gislason, T., \& Kristbjarnarson, H. (2002). Sleep and sleep habits from childhood to young adulthood over a 10-year period. Journal of Psychosomatic Research, 53, 529-537. http:// dx.doi .org/10.1016/S0022-3999(02)00444-0

U.S. Department of Agriculture Economic Research Service. (2003). Measuring rurality: Rural-urban continuum codes. Retrieved from http:// webarchives.cdlib.org/sw1wp9v27r/http:/ ers.usda .gov/Briefing/Rurality/RuralUrbCon/

U.S. Department of Education, Office of Planning, Evaluation and Policy Development, Performance Information Management Service. (2012). Free 
and reduced-price lunch eligibility data in EDFacts: A white paper on current status and potential changes. Washington, DC.

U.S. Department of Health and Human Services, Substance Abuse and Mental Health Services Administration. (2008). Results from the 2008 national survey on drug use and health: National findings. Retrieved from http://www.samhsa.gov/ data/nsduh/2k8nsduh/2k8results.pdf

Wahl, O. F. (2002). Children's views of mental illness: A review of the literature. Psychiatric Rehabilitation Skills, 6, 134-158. http://dx.doi.org/ 10.1080/10973430208408430

Wahlstrom, K. (2002). Changing times: Findings from the first longitudinal study of later high school start times. Sleep, 86, 3-21.

Watanabe, N., Furukawa, T. A., Shimodera, S., Morokuma, I., Katsuki, F., Fujita, H., . . Perlis, M. L. (2011). Brief behavioral therapy for refractory insomnia in residual depression: An assessor-blind, randomized controlled trial. Journal of Clinical Psychiatry, 72, 1651-1658. http://dx.doi.org/ 10.4088/JCP.10m06130gry

Werner, H., Molinari, L., Guyer, C., \& Jenni, O. G. (2008). Agreement rates between actigraphy, diary, and questionnaire for children's sleep patterns. Archives of Pediatrics \& Adolescent Medicine,
162, 350-358. http://dx.doi.org/10.1001/archpedi .162 .4 .350

Wittmann, M., Dinich, J., Merrow, M., \& Roenneberg, T. (2006). Social jetlag: Misalignment of biological and social time. Chronobiology International, 23, 497-509. http://dx.doi.org/10.1080/ 07420520500545979

Wolfson, A. R., \& Carskadon, M. A. (1998). Sleep schedules and daytime functioning in adolescents. Child Development, 69, 875- 887. http:// dx.doi .org/10.1111/j.1467-8624.1998.tb06149.x

Wolfson, A. R., Carskadon, M. A., Acebo, C., Seifer, R., Fallone, G., Labyak, S. E., \& Martin, J. L. (2003). Evidence for the validity of a sleep habits survey for adolescents. Sleep, 26, 213-216.

Yang, C. K., Kim, J. K., Patel, S. R., \& Lee, J. H. (2005). Age-related changes in sleep/wake patterns among Korean teenagers. Pediatrics, 115, 250 -256. http://dx.doi.org/10.1542/peds.2004$0815 \mathrm{G}$

Zisapel, N. (2007). Sleep and sleep disturbances: Biological basis and clinical implications. Cellular and Molecular Life Sciences, 64, 1174-1186. http://dx.doi.org/10.1007/s00018-007-6529-9 